\title{
A COMPARATIVE STUDY OF INTRATHECAL ROPIVACAINE-FENTANYL AND BUPIVACAINE-FENTANYL FOR LOWER LIMB ORTHOPAEDIC SURGERIES
}

\author{
Padmanabhan K. R. ${ }^{1}$, Vijayendran Rajendran' ${ }^{2}$ S. Ramadevi ${ }^{3}$
}

${ }^{1}$ Assistant Professor, Department of Anaesthesiology, Chengalpattu Medical College.

${ }^{2}$ Assistant Professor, Department of Anaesthesiology, Chengalpattu Medical College.

${ }_{3}^{3}$ Assistant Professor, Department of Anaesthesiology, Chengalpattu Medical College.

ABSTRACT

\section{BACKGROUND}

The aim of the study was to compare the efficacy and safety of intrathecal ropivacaine-fentanyl (RF) with bupivacaine-fentanyl (BF) for lower limb orthopaedic surgeries.

\section{METHODS AND MATERIALS}

In this Single Centred, Prospective, Randomised, Parallel group, Double-Blind study, sixty patients were randomly allocated to receive either intrathecal $15 \mathrm{mg}$ of $0.5 \%$ ropivacaine (isobaric) with $25 \mathrm{mcg}$ fentanyl (Group RF) or $15 \mathrm{mg}$ of $0.5 \%$ bupivacaine (isobaric)with $25 \mathrm{mcg}$ fentanyl (Group BF). The onset, duration, spread of sensory and motor block, haemodynamic parameters and side effects were recorded. Data analysis was done by using SPSS software and Sigma Stat 3.5 version (2012).

\section{RESULTS}

Time to reach highest sensory level, complete motor block and two segment sensory regression time is also comparable. The motor recovery to Bromage scale 1 was faster in Group RF. The haemodynamic stability was better in Group RF. Time duration of analgesia was prolonged in Group BF than RF.

\section{CONCLUSION}

Intrathecal RF provided satisfactory anaesthesia with haemodynamic stability for lower limb orthopaedic surgeries. It provides a lesser sensory and a shorter duration of motor block compared to BF, which is a desirable feature for early ambulation, voiding and physiotherapy.

\section{KEYWORDS}

Ropivacaine, Bupivacaine, Fentanyl, Intrathecal, Orthopaedic Surgery.

HOW TO CITE THIS ARTICLE: Padmanabhan KR, Rajendran V, Ramadevi S. A comparative study of intrathecal ropivacaine-fentanyl and bupivacaine-fentanyl for lower limb orthopaedic surgeries. J. Evolution Med. Dent. Sci. 2016;5(87):6437-6442, D0I: $10.14260 /$ jemds/2016/1457

\section{BACKGROUND}

Spinal Anaesthesia is the widely used method for lower limb orthopaedic surgeries, providing a faster onset and effective motor and sensory blockade. It is simple, easy to perform and has got a definite endpoint. Intrathecal bupivacaine is widely used in spinal anaesthesia over a long period of time.

In this setting, a newer drug ropivacaine has emerged, which is being widely used for epidural blocks and nerve plexus blocks. Ropivacaine has an improved safety profile over bupivacaine with respect to central nervous system and cardiotoxic potential. Though ropivacaine is being used frequently, in epidural and nerve blocks, the literature regarding its use in intrathecal route is sparse.

\section{Aim of the Study}

The aim of study is to compare the efficacy and safety of intrathecal Ropivacaine-Fentanyl and Bupivacaine-Fentanyl for lower limb Orthopaedic surgeries with respect to

Financial or Other, Competing Interest: None.

Submission 23-09-2016, Peer Review 16-10-2016,

Acceptance 24-10-2016, Published 28-10-2016.

Corresponding Author:

Dr. Padmanabhan K. R,

\#No. 70, Kancheepuram High Road,

Flat A, Ground Floor,

Ranga Apartments, Chengalpattu-603002.

E-mail: sharmeelapad1@gmail.com

DOI: $10.14260 /$ jemds/2016/1457
1. Primary Outcome- Spinal block characteristics.

2. Secondary Outcome- Haemodynamic effects and side effects.

\section{MATERIALS AND METHODS}

It is a single centred, prospective, randomised, parallel group, double-blind study. This study was done in Government Chengalpattu Medical College Hospital at Department of Anaesthesiology during the period June 2016 to August 2016.

After obtaining institutional ethical committee approval, 60 patients between the age group of $18-60$, who were posted for elective lower limb orthopaedic surgeries were recruited for the study. These 60 patients were randomised using a computer generated table, into two groups of 30 patients each as follows-

Group RF- $15 \mathrm{mg}$ of $0.5 \%$ Ropivacaine (3.0 mL isobaric) + 25 mcg Fentanyl $(0.5 \mathrm{~mL})$

Group BF- $15 \mathrm{mg}$ of $0.5 \%$ Bupivacaine ( $3.0 \mathrm{~mL}$ isobaric) + 25 mcg Fentanyl (0.5 mL)

\section{Inclusion Criteria}

- ASA physical status I \& II.

- Age 18-60 years.

- Both genders.

- Lower limb orthopaedic surgery.

\section{Exclusion Criteria}

- Known hypersensitivity to any of the test drugs.

- Any contraindication to spinal anaesthesia.

- Cardiac arrhythmias. 


\section{Procedure/Masking}

Pre-filled labelled syringes loaded with the drugs were prepared by an anaesthesiologist not participating in the study. The anaesthesiologist who did the intervention and observation was unaware of the contents of the syringes and the group allocation.

When the patient arrived in the operation room, IV access was established, and $500 \mathrm{~mL}$ of RL was started. Multipara monitor attached, and baseline parameters - EGG, NIBP, SPO2, respiratory rate were recorded. After skin infiltration with $2 \%$ lidocaine, 25G Quincke needle was inserted through L3-4 interspace in the midline, with the patient in sitting position. Correct placement of the needle was identified by free flow of cerebrospinal fluid and $3.5 \mathrm{~mL}$ of the study drug was injected over 10 seconds, and the patient was then placed supine.

Standard monitoring was used throughout the surgical procedure. ECG and pulse oximetry were continuously monitored, while NIBP was measured at 5-min. intervals. Heart rate and NIBP were recorded before intrathecal injection, 3, 5, 15, 30 minutes after the intrathecal drug administration, and thereafter every 30 minutes till the end of the surgery and one hour after the end of the surgery, at the ward. Any hypotension (Systolic blood pressure lower than $20 \%$ from the baseline) was treated with IV ephedrine $6 \mathrm{mg}$ and bradycardia (Heart rate $<50 / \mathrm{min}$.) incidents were treated with IV atropine $0.6 \mathrm{mg}$ increments.

\section{Parameters Observed/Primary}

\section{Spinal Block Characteristics}

- Time to reach peak sensory level - Pinprick test.

- $\quad$ Time to reach peak motor block - Bromage scale grade 3.

- Two segment sensory regression time.

- $\quad$ Time to motor regression to Bromage scale grade 1.

- Duration of analgesia.

\section{Post-Operative Period}

- $\quad$ Time to first analgesic demand (VAS > 4)

\section{Secondary}

- Heart Rate $(<50 /$ min.-Bradycardia).

- $\quad$ Blood Pressure $>20 \%$ fall from baseline SBP-Hypotension).

- Oxygen Saturation.

- Pruritus.

- Nausea.

- Vomiting.

- $\quad$ Shivering.

\begin{tabular}{|c|c|}
\hline Score & Response \\
\hline 0 & Normal Sensation \\
\hline 1 & Loss of Pinprick Sensation -Analgesia \\
\hline 2 & Loss of Touch Sensation - Anaesthesia \\
\hline \multicolumn{2}{|c|}{ Table I. Sensory Score } \\
\hline
\end{tabular}

\begin{tabular}{|c|c|c|}
\hline Grade & Response & $\begin{array}{c}\text { Degree of } \\
\text { Motor Block }\end{array}$ \\
\hline 0 & No Motor Block & Nil (0\%) \\
\hline 1 & $\begin{array}{c}\text { Unable to Raise } \\
\text { the Straight Leg }\end{array}$ & Partial (33\%) \\
\hline 2 & $\begin{array}{c}\text { Unable to Flex the } \\
\text { Knee Against } \\
\text { Resistance }\end{array}$ & $\begin{array}{c}\text { Almost Complete } \\
(66 \%)\end{array}$ \\
\hline 3 & $\begin{array}{c}\text { Unable to Flex } \\
\text { the Ankle }\end{array}$ & Complete \\
\hline \multicolumn{2}{|c|}{ Table II. Bromage Motor Scale } \\
\hline
\end{tabular}

Time of Onset of Sensory Block

The time interval between end of anaesthetic injection and appearance of cutaneous analgesia in the dermatomes assessed by the pinprick test using $20 \mathrm{G}$ hypodermic needle in $\mathrm{T}-12, \mathrm{~T}-10, \mathrm{~T}-8, \mathrm{~T}-6$ or higher levels (T-4).

\section{Motor Block Duration}

It is the time taken between administration of anaesthetic and the attainment of grade 0 in Bromage motor scale.

\section{Two Segment Sensory Regression Time}

The time taken for the sensory block to regress two segment down from the maximum level of blockade is defined as the two segment regression time.

\section{Duration of Analgesia}

It is the time of administration of anaesthetic and the disappearance of cutaneous level of sensation at each dermatomal level.

\section{Post-0p Analgesia Duration}

The time between the administration of anaesthetic and time of analgesic requirement (Visual analogue scale $>4$ ) in PACU.

\begin{tabular}{|llllllllll|}
\hline 1 & 2 & 3 & 4 & 5 & 6 & 7 & 8 & 9 & 10 \\
\hline
\end{tabular}

\section{Visual Analogue Scale}

\section{RESULTS}

\section{Statistical Analysis}

The information which was collected regarding all the selected cases were recorded in a master chart. Data analysis was done with the help of computer by using SPSS software and Sigma Stat 3.5 version (2012). Using this software, percentage, mean, standard deviation and 'p' value were calculated through one way ANOVA, and Chi square test and a $P$ value of $<0.05$ was taken as significant.

After an initial moderate fall produced by the sympathetic blockade in both groups, the systolic BP got stabilised after 90 min. in RF group, indicated by the recovery of BP to a higher level comparing to $\mathrm{BF}$ group, This reflects the better haemodynamic stability in RF group.

There is a statistically significant difference among the two groups with respect to systolic blood pressure.

This also coincides with the early recovery of motor power in RF group, when compared to the BF group.

\begin{tabular}{|c|c|c|c|c|c|}
\hline Systolic BP & Group RF & Group BF & SD & SD & P \\
\hline Min. 0 & 124.6 & 121.5 & 3.73 & 2.45 & $<0.001$ \\
\hline 3 & 122.4 & 118.5 & 4.79 & 4.52 & 0.002 \\
\hline 5 & 121.2 & 116.5 & 3.52 & 4.31 & $<0.001$ \\
\hline 15 & 116.9 & 115.3 & 2.55 & 1.91 & 0.006 \\
\hline 30 & 109.3 & 111.8 & 2.02 & 2.76 & $<0.001$ \\
\hline 60 & 107.6 & 108.5 & 2.88 & 3.98 & 0.333 \\
\hline 90 & 108.0 & 106.7 & 2.70 & 3.15 & 0.021 \\
\hline 120 & 113.2 & 107.8 & 2.24 & 1.06 & $<0.001$ \\
\hline 150 & 114.2 & 109.9 & 2.49 & 0.96 & $<0.001$ \\
\hline 180 & 118.7 & 111.0 & 1.51 & 1.47 & $<0.001$ \\
\hline 210 & 119.1 & 111.8 & 1.76 & 1.16 & $<0.001$ \\
\hline 240 & 118.8 & 111.9 & 3.24 & 1.88 & $<0.001$ \\
\hline 270 & 119.0 & 114.3 & 2.44 & 2.20 & $<0.001$ \\
\hline 300 & 118.5 & 116.0 & 2.79 & 1.88 & $<0.001$ \\
\hline Min. 330 & 119.1 & 116.0 & 0.83 & 1.68 & $<0.001$ \\
\hline \multicolumn{7}{|c|}{ Table III. Systolic Blood Pressure } \\
\hline
\end{tabular}




\section{Jemds.com}

Original Research Article

There was statistically significant difference in the systolic blood pressure between the two groups from 120 to 240 minutes. i.e. $p<0.05$. There is early stabilisation of systolic BP

Duration of Motor Block/Ropivacaine

Duration of motor block in minutes. in group RF.

\begin{tabular}{|l|l|l|l|l|l|l|l|l|l|l|l|l|l|}
\hline $\mathbf{0}$ & $\mathbf{5}$ & $\mathbf{1 0}$ & $\mathbf{3 0}$ & $\mathbf{6 0}$ & $\mathbf{9 0}$ & $\mathbf{1 2 0}$ & $\mathbf{1 5 0}$ & $\mathbf{1 8 0}$ & $\mathbf{2 1 0}$ & $\mathbf{2 4 0}$ & $\mathbf{2 7 0}$ & $\mathbf{3 0 0}$ & $\mathbf{3 3 0}$ \\
\hline \multicolumn{10}{|c|}{ Table IV } \\
\hline
\end{tabular}

\begin{tabular}{|c|c|c|c|c|c|c|c|c|c|c|c|c|c|}
\hline 0 & 2 & 3 & 3 & 3 & 3 & 3 & 2 & 2 & 2 & 2 & 1 & 1 & 1 \\
\hline 0 & 3 & 3 & 3 & 3 & 3 & 3 & 3 & 3 & 3 & 3 & 2 & 1 & 1 \\
\hline 0 & 3 & 3 & 3 & 3 & 3 & 3 & 3 & 2 & 2 & 2 & 2 & 1 & 1 \\
\hline 0 & 3 & 3 & 3 & 3 & 3 & 3 & 2 & 2 & 2 & 2 & 2 & 1 & 0 \\
\hline 0 & 3 & 3 & 3 & 3 & 3 & 3 & 3 & 3 & 3 & 1 & 0 & 0 & 0 \\
\hline 0 & 3 & 3 & 3 & 3 & 3 & 3 & 3 & 3 & 3 & 3 & 2 & 1 & 0 \\
\hline 0 & 2 & 3 & 3 & 3 & 3 & 3 & 3 & 2 & 2 & 2 & 2 & 1 & 1 \\
\hline 0 & 3 & 3 & 3 & 3 & 3 & 3 & 1 & 1 & 1 & 1 & 0 & 0 & 0 \\
\hline 0 & 3 & 3 & 3 & 3 & 3 & 3 & 3 & 2 & 2 & 1 & 1 & 1 & 0 \\
\hline 0 & 3 & 3 & 3 & 3 & 3 & 3 & 3 & 2 & 2 & 2 & 1 & 1 & 0 \\
\hline 0 & 3 & 3 & 3 & 3 & 3 & 3 & 2 & 2 & 1 & 1 & 0 & 1 & 0 \\
\hline 0 & 2 & 3 & 3 & 3 & 3 & 3 & 3 & 2 & 2 & 2 & 1 & 1 & 0 \\
\hline 0 & 3 & 3 & 3 & 3 & 3 & 3 & 3 & 2 & 2 & 1 & 1 & 0 & 0 \\
\hline 0 & 3 & 3 & 3 & 3 & 3 & 3 & 3 & 3 & 3 & 3 & 2 & 1 & 1 \\
\hline 0 & 3 & 3 & 3 & 3 & 3 & 3 & 2 & 2 & 2 & 1 & 1 & 0 & 0 \\
\hline 0 & 3 & 3 & 3 & 3 & 3 & 3 & 3 & 2 & 1 & 1 & 0 & 0 & 0 \\
\hline 0 & 2 & 3 & 3 & 3 & 3 & 3 & 3 & 3 & 2 & 1 & 1 & 0 & 0 \\
\hline 0 & 3 & 3 & 3 & 3 & 3 & 3 & 3 & 3 & 3 & 1 & 1 & 1 & 1 \\
\hline 0 & 3 & 3 & 3 & 3 & 3 & 3 & 2 & 2 & 1 & 1 & 0 & 0 & 0 \\
\hline 0 & 3 & 3 & 3 & 3 & 3 & 3 & 3 & 3 & 2 & 1 & 1 & 1 & 0 \\
\hline 0 & 3 & 3 & 3 & 3 & 3 & 3 & 3 & 3 & 2 & 1 & 1 & 1 & 0 \\
\hline 0 & 2 & 3 & 3 & 3 & 3 & 3 & 3 & 3 & 3 & 1 & 1 & 0 & 0 \\
\hline 0 & 3 & 3 & 3 & 3 & 3 & 3 & 2 & 2 & 1 & 1 & 0 & 0 & 0 \\
\hline 0 & 3 & 3 & 3 & 3 & 3 & 3 & 3 & 3 & 1 & 1 & 1 & 1 & 0 \\
\hline 0 & 3 & 3 & 3 & 3 & 3 & 3 & 3 & 3 & 1 & 1 & 1 & 1 & 0 \\
\hline 0 & 3 & 3 & 3 & 3 & 3 & 3 & 3 & 3 & 1 & 1 & 1 & 0 & 0 \\
\hline 0 & 3 & 3 & 3 & 3 & 3 & 3 & 3 & 2 & 1 & 1 & 1 & 1 & 1 \\
\hline 0 & 2 & 3 & 3 & 3 & 3 & 3 & 3 & 3 & 1 & 1 & 1 & 0 & 0 \\
\hline 0 & 3 & 3 & 3 & 3 & 3 & 3 & 3 & 3 & 1 & 1 & 1 & 0 & 0 \\
\hline 0 & 3 & 3 & 3 & 3 & 3 & 3 & 3 & 3 & 1 & 1 & 1 & 1 & 1 \\
\hline
\end{tabular}

\section{Bromage Scale}

There is an early recovery of motor block in ropivacaine-fentanyl group when compared to bupivacaine-fentanyl group. Most patients had full motor recovery by 300 minutes.

\begin{tabular}{|c|c|c|c|c|c|c|c|c|c|c|c|c|c|}
\hline $\mathbf{0}$ & 5 & 10 & 30 & 60 & 90 & 120 & 150 & 180 & 210 & 240 & 270 & 300 & 330 \\
\hline \multicolumn{14}{|c|}{ Table V. Bupivacaine- Duration of Motor Block in Minutes } \\
\hline
\end{tabular}




\begin{tabular}{|c|c|c|c|c|c|c|c|c|c|c|c|c|c|}
\hline 0 & 3 & 3 & 3 & 3 & 3 & 3 & 3 & 3 & 3 & 2 & 2 & 1 & 1 \\
\hline 0 & 3 & 3 & 3 & 3 & 3 & 3 & 3 & 3 & 2 & 2 & 2 & 1 & 1 \\
\hline 0 & 3 & 3 & 3 & 3 & 3 & 3 & 3 & 3 & 2 & 2 & 2 & 1 & 1 \\
\hline 0 & 3 & 3 & 3 & 3 & 3 & 3 & 3 & 3 & 2 & 1 & 1 & 1 & 0 \\
\hline 0 & 3 & 3 & 3 & 3 & 3 & 3 & 3 & 3 & 3 & 2 & 2 & 2 & 1 \\
\hline 0 & 3 & 3 & 3 & 3 & 3 & 3 & 3 & 3 & 2 & 2 & 2 & 1 & 1 \\
\hline 0 & 2 & 3 & 3 & 3 & 3 & 3 & 3 & 3 & 2 & 1 & 1 & 1 & 1 \\
\hline 0 & 3 & 3 & 3 & 3 & 3 & 3 & 3 & 3 & 2 & 2 & 2 & 2 & 1 \\
\hline 0 & 3 & 3 & 3 & 3 & 3 & 3 & 3 & 3 & 3 & 2 & 1 & 1 & 1 \\
\hline 0 & 3 & 3 & 3 & 3 & 3 & 3 & 3 & 3 & 2 & 2 & 2 & 2 & 1 \\
\hline 0 & 3 & 3 & 3 & 3 & 3 & 3 & 3 & 2 & 1 & 1 & 1 & 1 & 1 \\
\hline 0 & 2 & 3 & 3 & 3 & 3 & 3 & 3 & 3 & 3 & 2 & 2 & 1 & 1 \\
\hline 0 & 3 & 3 & 3 & 3 & 3 & 3 & 3 & 2 & 2 & 1 & 1 & 1 & 1 \\
\hline 0 & 2 & 3 & 3 & 3 & 3 & 3 & 3 & 3 & 2 & 2 & 2 & 2 & 1 \\
\hline 0 & 3 & 3 & 3 & 3 & 3 & 3 & 3 & 2 & 2 & 1 & 1 & 1 & 1 \\
\hline 0 & 3 & 3 & 3 & 3 & 3 & 3 & 3 & 3 & 2 & 2 & 2 & 2 & 1 \\
\hline 0 & 3 & 3 & 3 & 3 & 3 & 3 & 3 & 3 & 3 & 2 & 1 & 1 & 0 \\
\hline 0 & 3 & 3 & 3 & 3 & 3 & 3 & 3 & 2 & 1 & 1 & 1 & 1 & 1 \\
\hline 0 & 3 & 3 & 3 & 3 & 3 & 3 & 3 & 3 & 2 & 1 & 1 & 1 & 1 \\
\hline 0 & 3 & 3 & 3 & 3 & 3 & 3 & 3 & 2 & 1 & 1 & 1 & 1 & 1 \\
\hline 0 & 3 & 3 & 3 & 3 & 3 & 3 & 3 & 3 & 2 & 2 & 1 & 1 & 1 \\
\hline 0 & 3 & 3 & 3 & 3 & 3 & 3 & 3 & 3 & 2 & 1 & 1 & 1 & 1 \\
\hline 0 & 3 & 3 & 3 & 3 & 3 & 3 & 3 & 3 & 2 & 2 & 2 & 2 & 1 \\
\hline 0 & 3 & 3 & 3 & 3 & 3 & 3 & 3 & 3 & 2 & 2 & 1 & 1 & 0 \\
\hline 0 & 3 & 3 & 3 & 3 & 3 & 3 & 3 & 2 & 1 & 1 & 1 & 1 & 1 \\
\hline 0 & 3 & 3 & 3 & 3 & 3 & 3 & 3 & 2 & 1 & 1 & 1 & 1 & 1 \\
\hline 0 & 3 & 3 & 3 & 3 & 3 & 3 & 3 & 3 & 3 & 2 & 1 & 1 & 1 \\
\hline 0 & 3 & 3 & 3 & 3 & 3 & 3 & 3 & 2 & 2 & 2 & 2 & 1 & 1 \\
\hline 0 & 3 & 3 & 3 & 3 & 3 & 3 & 3 & 2 & 2 & 2 & 1 & 1 & 1 \\
\hline 0 & 3 & 3 & 3 & 3 & 3 & 3 & 3 & 3 & 1 & 1 & 1 & 1 & \\
\hline
\end{tabular}

The duration of motor block was prolonged in BF group as evidenced by more patients in Bromage scale 3 even in 180 minutes.

\begin{tabular}{|c|c|c|}
\hline $\begin{array}{c}\text { Duration of } \\
\text { Analgesia (min.) }\end{array}$ & Group RF & Group BF \\
\hline Mean & 242.27 & 289.2 \\
\hline SD & 12.81 & 16.38 \\
\hline p value & $<0.001$ Significant \\
\hline \multicolumn{2}{|c|}{ Table VI. Duration of Analgesia } \\
\hline
\end{tabular}

There is a statistical significance in the difference between the two groups $\mathrm{RF}$ and $\mathrm{BF}, \mathrm{p}$ value $<0.001$ i.e, the duration of analgesia is more in $\mathrm{BF}$ group.

\section{DISCUSSION}

Gaurav Kuthiala and Geeta Chaudhary et al[1] described that the lipophilicity of ropivacaine is less when compared to bupivacaine, and so is less likely to penetrate the large myelinated motor fibres; and so it has selective action on $\mathrm{A} \delta$ and $C$ nerves which were transmitting pain, comparing to $A \beta$ fibres, which are involved in the motor function.

Luck et al[2] used equal doses of hyperbaric bupivacaine, ropivacaine and levobupivacaine $(15 \mathrm{mg})$ intrathecally for elective surgery, and found that ropivacaine provided spinal anaesthesia of shorter duration when compared to levobupivacaine and bupivacaine, and they concluded that the recovery profile of ropivacaine is useful, where early mobilisation is required. e.g. orthopaedic surgeries for early physiotherapy.

Koltka et al[3] compared doses of equal potency of the isobaric bupivacaine- $13 \mathrm{mg}$ and ropivacaine-19.5 $\mathrm{mg}$ and, both with fentanyl- 20 mcg for the sub-arachnoid block in lower abdominal surgery. They found that the RF had a lower level of sensory block with a shorter duration of motor block, when compared to BF.

In a study by Lee et al [4], equal doses of intrathecal ropivacaine and bupivacaine $(10 \mathrm{mg})$ with $15 \mathrm{mcg}$ fentanyl were used for urology surgeries, and they reported that ropivacaine provided a similar level of sensory anaesthesia, but a shorter duration of motor block, in comparison to bupivacaine.

Chung CJ, Park JS, Yun SH, Hwang GB, Chin YJ [5] found in their study that adding fentanyl $10 \mathrm{mcg}$ with hyperbaric ropivacaine $18 \mathrm{mg}$ in spinal anaesthesia for caesarean section improves the quality of intraoperative anaesthesia and significantly increases the quality of analgesia in early postoperative period.

Graf BM[6] and his colleagues hypothesised that the isomers of ropivacaine had lesser cardio depressant effects compared to isomers of bupivacaine because of the replacement of butyl group by a propyl-terminal group.

Sangeeta Varun et al[7] study has a similar results of Luck et al study.

A Yegin et al,[8] Prashanth K Gupta[9] \& Singh[10] and his colleagues found in their study that adding fentanyl 25 micrograms intrathecally will improve the quality of analgesia significantly, and prolong the duration of intraoperative \& postoperative analgesia, without causing a substantial increase in the major side effects and reducing post-operative analgesic requirement.

Chaudhary et al[11] had conducted a study and showed that the addition of intrathecal fentanyl to ropivacaine may offer the advantage of haemodynamic stability, shorter duration of 
complete motor blockade, and without any increase in the frequency of major side effects.

Malinovsky JM[12] and his colleagues compared intrathecal use of ropivacaine to bupivacaine in patients scheduled for TURP. They concluded that using $15 \mathrm{mg}$ of intrathecal ropivacaine provides a similar motor and haemodynamic effects, but less potent anaesthesia when compared to $10 \mathrm{mg}$ of bupivacaine for endoscopic urological surgery.

D. Hughes et al[13] conducted a study aimed to reduce the incidence of motor blockade in combined spinal and epidural technique in labour analgesia. They compared the intrathecal use of bupivacaine $2.5 \mathrm{mg}$ with ropivacaine $2.5 \mathrm{mg}$, both with fentanyl 25 micrograms. They came to a conclusion that ropivacaine $2.5 \mathrm{mg}$, when used intrathecally in combination with fentanyl 25 micrograms, as part of a CSE technique had provided a safe and rapid onset of analgesia for labour, but with a lesser motor blockade when compared to a same dose of bupivacaine.

Anita R Chhabra et al[14] had compared the efficacies of intrathecal adjuvants with isobaric ropivacaine for major lower limb surgeries and observed that clonidine, when used as an adjuvant intrathecally, provided a denser and longer duration of motor blockade, prolonged duration of sensory blockade, and a longer duration of post-operative analgesia when compared to fentanyl.

Wahedi W et al[15] in their randomised, double-blind study, administered intrathecally two different doses of ropivacaine $5 \mathrm{mg} / \mathrm{mL}$ and $7.5 \mathrm{mg} / \mathrm{mL}$. A volume of $3 \mathrm{~mL}$ was injected intrathecally to forty patients and they recorded the spinal block characteristics. They concluded that ropivacaine results in long-lasting spinal anaesthesia at concentrations of $0.5 \%$ (5 $\mathrm{mg} / \mathrm{mL})$ and $0.75 \%(7.5 \mathrm{mg} / \mathrm{mL})$.

Buckenmaier CC, Nielsen KC, Pietrobon R, Klein SM, Martin $\mathrm{AH}$, Greengrass RA, and Steele SM[16] had compared the efficacy of ropivacaine as an alternative to lidocaine, in patients undergoing anorectal procedures as outpatient basis.

They compared intrathecal administration of hyperbaric lidocaine $25 \mathrm{mg}$ with fentanyl 20 micrograms with hyperbaric ropivacaine $4 \mathrm{mg}$ with fentanyl 20 micrograms. They concluded that intrathecal hyperbaric small-dose of ropivacaine with fentanyl is an acceptable anaesthetic for anorectal surgeries.

Venkata $\mathrm{HG}^{[17]}$ and his colleagues compared the duration of analgesia and haemodynamics using a low dose (7.5 mg) bupivacaine- fentanyl mixture with a conventional dose $(10$ $\mathrm{mg}$ ) of hyperbaric bupivacaine for cesarean section. They compared between $10 \mathrm{mg}$ of hyperbaric bupivacaine, and a drug combination containing 25 micrograms fentanyl and 7.5 mg of hyperbaric bupivacaine, posted for elective caesarean section. They concluded that in caesarean section, the combination of low dose bupivacaine $7.5 \mathrm{mg}$ and fentanyl 25 micrograms is haemodynamically stable, and has a prolonged duration of analgesia when compared to bupivacaine alone.

Bogra J et al[18] compared different doses of intrathecal bupivacaine alone and in combination with fentanyl, for caesarean section. The patient received one of the following dose i.e. $8 \mathrm{mg}, 10 \mathrm{mg}, 12.5 \mathrm{mg}$ of bupivacaine alone, or in combination with 12.5 micrograms of fentanyl. They concluded fentanyl is able to reduce the dose of bupivacaine, due to its synergistic effect on bupivacaine, and therefore reducing its harmful effects.
Van Kleef JW et al[19] aimed to determine the safety and clinical efficacy of ropivacaine, as a local anaesthetic for spinal anaesthesia. They studied by using either $3 \mathrm{~mL}$ of isobaric solution containing $0.5 \%$ (15 mg), or $0.75 \%$ (22.5 mg) ropivacaine. They concluded that subarachnoid injection of isobaric ropivacaine solutions results in a variable analgesic spread, and mostly accompanied by a good quality of motor block, in particular with the $0.75 \%$ solution.

Ropivacaine is a long acting, enantiomerically pure (S-enantiomer) amide local anaesthetic, and with a low lipid solubility. The low lipid solubility of ropivacaine relates the lesser duration of analgesia comparing to bupivacaine. Intrathecal ropivacaine, in animal studies has shown to produce effective sensory block, but the duration of motor block is shorter than intrathecal bupivacaine, with no signs of neurological side effects.

The early motor recovery of ropivacaine is due to the blockade of nerve fibres involved in transmission of pain (A $\delta$ and $\mathrm{C}$ fibres) to a greater degree, comparing to controlling of motor functions ( $\mathrm{A} \beta$ fibres). This feature favours its use where early ambulation is needed as in orthopaedic surgeries for starting physiotherapy. This feature also allows for the detection of any neurological side-effects, if any, occurred.

The present study has demonstrated that using either ropivacaine or bupivacaine intrathecally, with fentanyl as an adjuvant has provided satisfactory anaesthetic conditions for lower limb ortho surgeries. Most of the subarachnoid block characteristics were similar. There was a significant early motor recovery in RF group with haemodynamic stability, but BF provided a prolonged duration of post-operative analgesia.

We proposed to study the efficacy of ropivacaine for major orthopaedic surgeries as an alternative to bupivacaine, using equimilligram dose (15 $\mathrm{mg}$ ) as used by Luck et al. While maintaining the advantage of low dose local anaesthetic intrathecally, the use of analgesic adjuvants can improve the quality of intraoperative anaesthesia. Lipid soluble opioids such as sufentanil and fentanyl are the most commonly used adjuvants. Studies have shown that intrathecal opioids can enhance greatly the duration of analgesia of subtherapeutic doses of local anaesthetics. Fentanyl added to local anaesthetic agent intrathecally seems to be the most frequently used combination in spinal anaesthesia, to enhance and increase the duration of sensory block, without intensifying the duration of motor blockade or prolonging the recovery from spinal anaesthesia.

Both intrathecal RF and BF produced an initial moderate fall in blood pressure in keeping with the expected sympathetic blockade produced by the spinal anaesthesia. Although the systolic BP stabilised after $30 \mathrm{~min}$., there was a statistically significant difference among the two groups from 120 to 240 minutes, where the systolic BP comes near the baseline values in RF group. This recovery profile of systolic blood pressure in the ropivacaine-fentanyl group more or less coincides with the recovery of motor block.

Our results are consistent with Lee et al as we observed comparable levels of highest dermatome block, the time taken to reach the peak sensory and motor level and the two segment sensory regression time. The motor block was significantly shorter with Group RF, although it outlasted the duration of surgery.

This feature is desirable as it encourages early ambulation, voiding and physiotherapy. Neurological side effects, if any, 
can also be detected early. The mean time duration of analgesia is significantly prolonged in Group BF when compared to Group RF.

No patient in either group required intraoperative analgesia, since the duration of surgery is within the duration of sensory block in both groups.

Intraoperative hypotension requiring treatment with ephedrine occurred in 3 patients in Group RF as compared to 8 patients in Group BF. One patient in each group was also treated with $0.6 \mathrm{mg}$ IV atropine for bradycardia. The most common adverse effect noted was nausea and vomiting, experienced in both the groups. Shivering also occurred in both the groups.

\section{CONCLUSIONS}

Intrathecal Ropivacaine-Fentanyl provides a satisfactory anaesthesia and has a better haemodynamic stability for lower limb orthopaedic surgeries. The shorter duration of motor block compared to intrathecal Bupivacaine-Fentanyl is helpful in terms of early ambulation, voiding and for starting physiotherapy earlier.

Although certain trends could be established in this study with encouraging results, further studies with larger sample sizes are needed to form a definitive opinion regarding the application of intrathecal ropivacaine.

\section{ACKNOWLEDGEMENTS}

We are very grateful to the Professors and Asst. Professors of Dept. of Orthopaedic Surgery. We also thank Professors, Asst. Professors and PGs of Dept. of Anaesthesiology. We are thankful to the institutional ethical committee for their guidance and approval to the study. We thank all the cooperative patients who were subjected for this study. We also wish to state that no financial or material support was obtained for this study.

\section{REFERENCES}

1. Kuthiala G, Chaudhary G. Ropivacaine: a review of its pharmacology and clinical use. Indian J Anaesth 2011;55(2):104-10.

2. Luck JF, Fettes PD, Wildsmith JA. Spinal anaesthesia for elective surgery: a comparison of hyperbaric solutions of racemic bupivacaine, levobupivacaine and ropivacaine. British Journal Anaesth 2008;101(5):705-10.

3. Koltka K, Uludag E, Senturk M, et al. Comparison of equipotent doses of ropivacaine-fentanyl and bupivacaine-fentanyl in spinal anaesthesia for lower abdominal surgery. Anaesth Intensive Care 2009; 37(6):923-8.

4. Lee YY, Ngan Kee WD, Muchhal K, et al. Randomized double-blind comparison of ropivacaine-fentanyl and bupivacaine-fentanyl for spinal anaesthesia for urological surgery. Acta Anaesthesiol Scand 2005;49(10):1477-82.

5. Chung CJ, Yun SH, Hwang GB, et al. Intrathecal fentanyl added to hyperbaric ropivacaine for cesarean delivery. Reg Anesth Pain Med 2002;27(6):600-3.
6. Graf BM, Abraham I, Eberbach N, et al. Differences in cardiotoxicity of bupivacaine and ropivacaine are the result of physicochemical and stereoselective properties. Anesthesiology 2002;96(6):1427-34.

7. Varun S, Srivastava M, Maurya I, et al. A clinical prospective, randomized study to compare intrathecal isobaric bupivacaine-fentanyl and isobaric ropivacainefentanyl for lower abdominal and lower limb surgeries. Anaesth, Pain \& Intensive Care 2012;16(3):237-42.

8. Yegin A, Sanli A, Hadimioglu N, et al. Intrathecal fentanyl added to hyperbaric ropivacaine for transurethral resection of the prostate. Acta Anaesthesiol Scand 2005;49(3):401-5.

9. Gupta K, Singh S, Sharma D, et al. Intrathecal fentanyl as an adjuvant to $0.75 \%$ isobaric ropivacaine for infraumbilical surgery under subarachnoid block: a prospective study. Saudi Journal of Anaesthesia 2014;8(1):64-8.

10. Singh H, Yang J, Thornton $\mathrm{K}$, et al. Intrathecal fentanyl prolongs sensory bupivacaine spinal block. Can J Anaesth 1995;42(11):987-91.

11. Chaudhary A, Bogra J, Singh PK, et al. Efficacy of spinal ropivacaine versus ropivacaine with fentanyl in transurethral resection operations. Saudi Journal of Anaesthesia 2014;8(1):88-91.

12. Malinovsky JM, Charles F, Kick 0 , et al. Intrathecal anesthesia: ropivacaine versus bupivacaine. Anesth Analg 2000;91(6):1457-60.

13. Hughes D, Hill D, Fee JP. Intrathecal ropivacaine or bupivacaine with fentanyl for labour. $\mathrm{Br} \mathrm{J}$ Anaesth 2001;87(5):733-7.

14. Chhabra AR, Jagtap SR, Dawoodi SF. Comparison of clonidine versus fentanyl as an adjuvant to intrathecal ropivacaine for major lower limb surgeries: a randomized double-blind prospective study. Indian Journal of Pain 2013;27(3):170-4.

15. Wahedi $W$, Nolte $H$, Klein P. Ropivacaine for spinal anesthesia. A dose-finding study. Anaesthesist 1996;45(8):737-44.

16. Buckenmaier CC, Nielsen KC, Pietrobon R, et al. Smalldose intrathecal lidocaine versus ropivacaine for anorectal surgery in an ambulatory setting. Anesth Analg 2002;95(5):1253-7.

17. Venkata HG, Pasupuleti S, Pabba UG, et al. A randomized controlled prospective study comparing a low dose bupivacaine and fentanyl mixture to a conventional dose of hyperbaric bupivacaine for cesarean section. Saudi J Anaesth 2015;9(2):122-7.

18. Bogra J, Arora N, Srivastava P. Synergistic effect of intrathecal fentanyl and bupivacaine in spinal anesthesia for cesarean section. BMC Anesthesiol 2005;5(1):5.

19. van Kleef JW, Veering BT, Burm AG. Spinal anesthesia with ropivacaine: a double-blind study on the efficacy and safety of $0.5 \%$ and $0.75 \%$ solutions in patients undergoing minor lower limb surgery. Anesth Analg 1994;78(6):1125-30. 